\title{
Kin recognition and inbreeding reluctance in bumblebees*
}

\author{
Penelope R. Whitehorn, Matthew C. Tinsley, Dave Goulson \\ School of Biological and Environmental Sciences, University of Stirling, Stirling, FK9 4LA, UK
}

Received 12 January 2009 - Revised 24 March 2009 - Accepted 27 March 2009

\begin{abstract}
Inbreeding frequently has a costly impact on fitness, thus selection has favoured the evolution of kin recognition and inbreeding avoidance behaviour in many species. As haplodiploid Hymenoptera, bumblebees are susceptible to additional costs of inbreeding due to their single-locus complementary sex determination (sl-CSD) system, which means that incest can result in the production of costly diploid males. Here we test whether Bombus terrestris reproductives are able to discriminate between kin and non-kin and whether their willingness to mate is adjusted accordingly. We found that $B$. terrestris reproductives took significantly longer to mate with siblings compared to non-relatives. This indicates that this species exhibits kin recognition and uses this information to determine mating behaviour.
\end{abstract}

Bombus terrestris / mating / inbreeding avoidance / haplodiploidy

\section{INTRODUCTION}

In species that suffer from inbreeding depression, mechanisms to avoid mating with close relatives are expected to be selected for (Pusey and Wolf, 1996). Kin recognition is one such mechanism and close relatives can be identified using either environmental (extrinsic) or genetic (intrinsic) clues (Holmes and Sherman, 1983). Extrinsic kin recognition is often context based: individuals learn environmental cues, such as the scent of their nest environment, then identify kin as those possessing the same environmental cues (Holmes and Sherman, 1982). Intrinsic kin recognition is independent of learning and is mediated by recognition alleles: individuals bearing the same alleles consider one another as kin (Keller and Ross, 1998). Increasingly, the definition of kin recognition is restricted only to intrinsic mechanisms, although extrinsic mechanisms, such as nestmate recognition, can also lead to clear kin discrimination (Barnard and Aldhous, 1991;

Corresponding author: P.R. Whitehorn,

p.r.whitehorn@stir.ac.uk

* Manuscript editor: Jean-Noël Tasei
Todrank and Heth, 2003). Incest avoidance via kin discrimination has been reported for several insect species, including halictine bees (Smith and Ayasse, 1987), the field cricket Gryllus bimaculatus (Simmons, 1989), the ant Iridomyrmex humilis (Keller and Passera, 1993) the termite Zootemopsis nevadensis (Shellman-Reeve, 2001) and the cockroach Blattella germanica (Lihoreau et al., 2007).

It might be expected that bumblebees have evolved methods of kin recognition as they are particularly susceptible to costs of inbreeding due to their single-locus complementary sex determination (sl-CSD) system (Zayed and Packer, 2005). The sex-determining locus is polyallelic; individuals that are heterozygous develop into diploid females, whereas hemizygotes become haploid males. However, if individuals are homozygous at the sex locus they develop as diploid males. This occurs rarely in large outbreeding populations because many CSD alleles can be maintained by negative frequency dependant selection (Duchateau et al., 1994). However, genetic drift in small populations is expected to increase diploid male production (DMP) by reducing CSD allelic richness (Cook and Crozier, 1995). 
Bumblebee diploid males yield no genetic return for the resources invested in them. Bombus terrestris diploid males have smaller testes and fewer spermatozoa than haploid males, and hence suffer reduced fertility (Duchateau and Marien, 1995). Queens that do mate with diploid males may produce a viable colony containing triploid offspring, but the triploid queens are infertile (Ayabe et al., 2004). Additionally, as diploid males are produced from the first brood, the majority are on the wing too early in the season to encounter virgin queens. The social nature of bumblebees predisposes them to further costs of DMP: diploid males are produced instead of $50 \%$ of the female workforce and do not contribute to colony productivity. This slows the rate of colony growth in Bombus atratus under laboratory conditions (Plowright and Pallett, 1979) and significantly reduces survival of B. terrestris colonies in the field (Whitehorn et al., 2009).

Diploid males occur in rare and localised bumblebee species in the wild. In the Japanese bumblebee Bombus florilegus 28\% of sampled colonies contained diploid males; similarly, in the UK, 5\% of Bombus muscorum males were found to be diploid. In both cases this is thought to result from low genetic diversity, small population size and fragmentation (Takahashi et al., 2008; Darvill et al., 2006). Recent modelling has demonstrated that DMP can initiate a rapid extinction vortex (Zayed and Packer, 2005), which has implications for the persistence of small genetically impoverished populations of bumblebees. In contrast, in large populations the risk of matings between bees with identical sex determination locus genotype is low, so long as siblings do not mate. However, bumblebee nests often produce large numbers of queens and males simultaneously, so encounters between siblings are likely and inbreeding avoidance behaviour is therefore beneficial.

The mating behaviour of bumblebees has been well studied in the laboratory (Djegham et al., 1994; Tasei et al., 1998; Sauter and Brown, 2001; Baer, 2003). By comparison, little is known about inbreeding avoidance behaviours. One study suggested that at least two bumblebee species recognise kin; when given a choice queens of Bombus frigidus and Bombus bifarius preferentially mated with unrelated males (Foster, 1992). Males of these two species exhibit similar pre-mating behaviour known as 'patrolling', where males mark prominent objects with a pheromone and visit them sequentially to encounter potential mates attracted by the scent (Alford, 1975; Williams, 1991). In such a situation it is unlikely that reproductives will encounter both siblings and non-siblings at the same time and so choice experiments such as Foster's (1992) perhaps do not represent the natural situation. Here we take an alternative approach to investigate kin recognition in $B$. terrestris, another species in which males exhibit patrolling behaviour in the wild.

$B$. terrestris is an annual, primitively eusocial bumblebee species. Under natural conditions, queens emerge from hibernation in spring and individually found colonies. Once the first batch of offspring has been produced, they take over the tasks of foraging, brood care and nest maintenance. Towards the end of the colony cycle, usually in the late summer, sexuals (young queens and males) are produced and leave the nest to find mates. The young queens mate only once and then enter hibernation; the old queen, the workers and the males then die. The following spring the queens that have survived hibernation give rise to the next generation (Alford, 1975).

We present $B$. terrestris reproductives with either siblings or non-siblings and measure their propensity to mate. This may be a more realistic measure of inbreeding avoidance as a delayed propensity to mate in natural situations will reduce the chance of successful copulation.

\section{MATERIALS AND METHODS}

\subsection{Experimental protocol}

Eight laboratory colonies of B. terrestris, purchased from Koppert Biological Systems (The Netherlands) in February 2008, provided young queens and males. The colonies were checked each day and new sexuals that had emerged were removed and housed in single sex sibling groups. The sexuals were mated when between two and ten days 
old in mesh-sided flight cages $(70 \mathrm{~cm} \times 70 \mathrm{~cm} \times$ $70 \mathrm{~cm}$ ) between 1st April and 16th April 2008. The matings took place in the laboratory, adjacent to large windows, between $1000 \mathrm{~h}$ and $1500 \mathrm{~h}$ so there were considerable quantities of natural light.

Young queens from each colony were either offered their brothers as mates or unrelated males from one other randomly chosen colony. Bees were mated in groups ( $\mathrm{n}=15$ to 60 ), always in a 1:2 ratio of young queens to males. Only sibling groups were used, i.e. all males in the mating cage at any one time were brothers, and all queens were sisters. Mating pairs were removed from the flight cage during copulation. The mated queens then went into a separate study that we have published elsewhere, which required that we performed twice as many sibling matings as non-sibling matings. The willingness of queens to mate with their brothers compared to non-relatives was investigated by measuring the time between the release of bees into the flight cage and a copulation. All mating sessions were terminated after one hour. The proportions of mated and unmated queens were recorded for each mating batch where more than one mating occurred.

\subsection{Statistical analyses}

Data were analysed in Minitab 15 (Minitab Inc., State College, PA, USA) with a General Linear Model. The response variable, time to mate, was box-cox transformed to fulfil the assumptions of normality. Mate identity (sibling vs. nonsibling), maternal colony, number of individuals in the cage and their interactions were included in the model. The model was sequentially simplified by the step-wise removal of non-significant terms. A further General Linear Model was used to analyse an additional response variable, proportion of queens mated within a batch. Mate identity, maternal colony and number of individuals in the cage were included in the model, which was again sequentially simplified. For bees originating from each of the eight colonies, individual t-tests were carried out to determine the significance of differences between the time to mate for sib and non-sib matings. Tests did not assume equal variance and were uncorrected for multiple comparisons. Means are recorded \pm their standard errors throughout.

\section{RESULTS}

The mating behaviour of 173 young queens from eight colonies was recorded; 70 with non-relatives, 103 with siblings. A mean of 10.8 minutes $( \pm 0.94)$ passed before a sibling mating occurred, compared to a mean of only 4.5 minutes $( \pm 1.15)$ for a mating between non-relatives. Pooling the data in this way revealed a highly significant difference between sibling and non-sibling matings $\left(\mathrm{F}_{1,171}=22.21, P<0.001\right)$. Bees originated from eight maternal colonies; for offspring from seven of these, sibling matings were notably delayed relative to unrelated matings, in one case time to mate with siblings and nonrelatives was similar (see Fig. 1). Two-sample t-tests showed that these differences were significant for three out of the eight colonies ( $P$ ranged from 0.018 to 0.024 ).

Maternal colony, the number of bees in the mating cage and the interaction between the maternal colony and the identity of the mate did not significantly influence time to mate $\left(\mathrm{F}_{7,152}=0.70, P=0.70 ; \mathrm{F}_{5,152}=0.73\right.$, $P=0.60 ; \mathrm{F}_{7,152}=0.97, P=0.452$ respectively).

A mean proportion of $0.59( \pm 0.06)$ queens mated within non sibling batches, compared to a mean proportion of $0.43( \pm 0.05)$ queens within sibling batches. This difference was not significant $\left(\mathrm{F}_{1,22}=3.46, P=0.076\right)$. The proportion of mated queens was influenced by maternal colony $\left(\mathrm{F}_{7,23}=4.87, P=0.002\right)$ but not by the number of bees in the mating cage $\left(\mathrm{F}_{6,16}=0.94, P=0.497\right)$.

\section{DISCUSSION}

For the first time, this study has demonstrated that $B$. terrestris reproductives are less willing to mate with their siblings than with unrelated individuals. Successful copulations between siblings took more than twice as long to initiate than matings between non-relatives. This suggests that $B$. terrestris has the ability to recognise kin and modulates its mating behaviour accordingly. Additionally, a greater proportion of queens mated with non-relatives, compared to siblings, but this difference was 


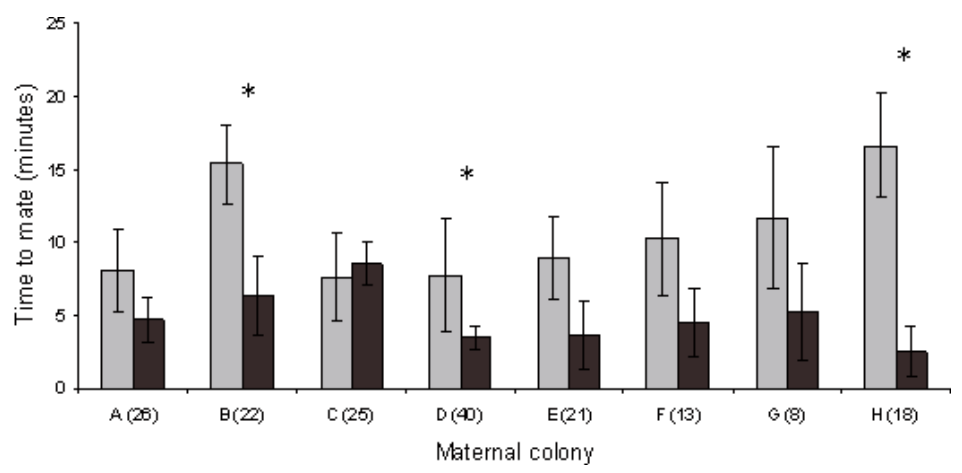

Figure 1. The mean time for reproductives from 8 colonies to copulate with siblings (light grey bars) and non-siblings (dark grey bars). Bars represent the least squares means and their standard errors as predicted by a GLM. The GLM demonstrated that significantly more time elapsed before a queen mated with a sibling compared to a non-relative. Asterisks mark individual within-colony differences that were significant with 2-sample t-tests. The $\mathrm{x}$-axis shows colony ID and sample size in parentheses.

not significant. Variation in the reluctance to mate existed between maternal colonies but the trend for delayed sib-mating was evident in experiments on bees from seven of the eight maternal colonies tested. Among-family variation is common in bumblebees and has been found in a number of different fitness traits (Gerloff et al., 2003; Gerloff and SchmidHempel, 2005).

A successful copulation is the result of a number of interacting factors, which can include male choice, female choice, male courtship behaviour, female response to this courtship and female reproductive status (Halliday, 1983). Several precopulatory behaviours occur in bumblebees. Conditions in the laboratory are too artificial for males to set up nuptial routes and exhibit their patrolling behaviour, but other behaviours that occur once potential mates have encountered each other can be observed. Males approach females, inspect them with their antennae and then attempt to copulate. Females respond to males in three ways, either by remaining immobile, flying away, or exhibiting threat behaviour by raising their middle legs (Djegham et al., 1994). However, it is not known how differences in these behaviours influence copulation success (Sauter and Brown, 2001).

Despite the uncertainty surrounding the role of precopulatory behaviours, it is likely that a successful copulation in bumblebees is ul- timately the result of female choice for two main reasons. Firstly, the queen controls the onset of copulation as she must move her sting for the male to be able to insert his genitalia; queens are very choosy, often rejecting many males in the laboratory (Djegham et al., 1994; Duvoisin et al., 1999) as well as in the field (Kindl et al., 1999). Secondly, because bumblebee queens mate only once (Estoup et al., 1995; Schmid-Hempel and Schmid-Hempel, 2000) and males are capable of mating many times (Tasei et al., 1998) selection acts more strongly on females to choose a mate that will maximise her fitness. This suggests that the different propensities to mate observed in our experiment were a result of variations in female behaviour and $B$. terrestris queens have the ability to recognise siblings.

$B$. terrestris colonies are almost invariably headed by a single, singly mated queen, ensuring high relatedness of all colony members. Queens may recognise siblings either because they are close kin or because they are nestmates; the former suggests they use intrinsic genetic cues, whereas the latter suggests extrinsic environmental cues are employed to determine mating relunctance. Because bumblebees are social insects it is possible that kin are recognised extrinsically through prior association as has been found in other species (for example, Frommen et al., 2007). Alternatively, an intrinsic mechanism may have developed. 
One such mechanism is known as phenotypic matching in which an individual recognises kin by assessing the similarities and differences between its own phenotype and that of unfamiliar conspecifics (Blaustein, 1983). This latter mechanism is thought to occur in the field cricket Gryllus bimaculatus where the females use their own cuticular compounds as a phenotypic template (Simmons, 1989).

It is beyond the scope of this paper to attempt to distinguish which method of discrimination $B$. terrestris may be employing. Nevertheless, whatever the underlying cognitive mechanisms, the behaviour observed in this study represents a clear example of kin discrimination (Tang-Martinez, 2001). These findings augment those of Foster (1992), who found that queens of $B$. frigidus and B. bifarius preferentially mated with unrelated males. In Foster's experiment the queens were given the choice between mating with a nestmate or a non-nestmate, which might suggest that queens compare males to see which are most different to themselves. However, in our experiment $B$. terrestris queens only ever encountered one type of male and still appeared to discriminate between kin and non-kin.

Such kin recognition and avoidance behaviour is expected to have been strongly selected for in bumblebees to avoid the costs of diploid male production that result from a mating between siblings. This is in accordance with the model of genetic complementarity, which assumes that females do not always choose a male with intrinsically superior genes. They may instead choose males with whom they have a higher genetic compatibility, i.e. the viability of offspring depends on the interaction between the male and female genotypes (Tregenza and Wedell, 2002). Many studies of genetic complementarity have focused on polyandrous species where there is the potential for postcopulatory female choice (Birkhead and Pizzari, 2002; Colegrave et al., 2002). However, the majority of bumblebee species are monoandrous (Estoup et al., 1995; Schmid-Hempel and Schmid-Hempel, 2000) and in such species there must be some precopulatory indication of a male's relatedness. In the solitary wasp Philanthus triangulum this indication is through variation in the male's sex pheromone, which is more similar within than among families (Herzner et al., 2006). In some social Hymenoptera, this indication has been shown to be mediated through the chemical composition of cuticular hydrocarbon recognition pheromones, for example in the bee Lasioglossum zephyrum (Smith and Wenzel, 1988), the wasp, Polistes fuscatus (Gamboa et al., 1996) and the fire ant Solenopsis invicta (Keller and Ross, 1998).

The delayed propensity for B. terrestris to mate with siblings, demonstrated in this study, is likely to have been selected for as an inbreeding avoidance mechanism. This in turn decreases the production of costly diploid males. However, in small fragmented populations, mate choice is substantially reduced and sibling matings and diploid male production may become inevitable. This endorses the importance of habitat, and hence population connectivity when considering bumblebee conservation.

\section{ACKNOWLEDGEMENTS}

We thank Steph O'Connor, Christiane Nitsch and Calum Brown for help with the laboratory work. We are grateful to James Weir for technical support. PRW was funded by a NERC studentship.

\section{Reconnaissance de la parentèle et mécanismes pour éviter la consanguinité chez les bourdons.}

Bombus terrestris / accouplement / consanguinité / haplodiploidie / reconnaissance de parentèle

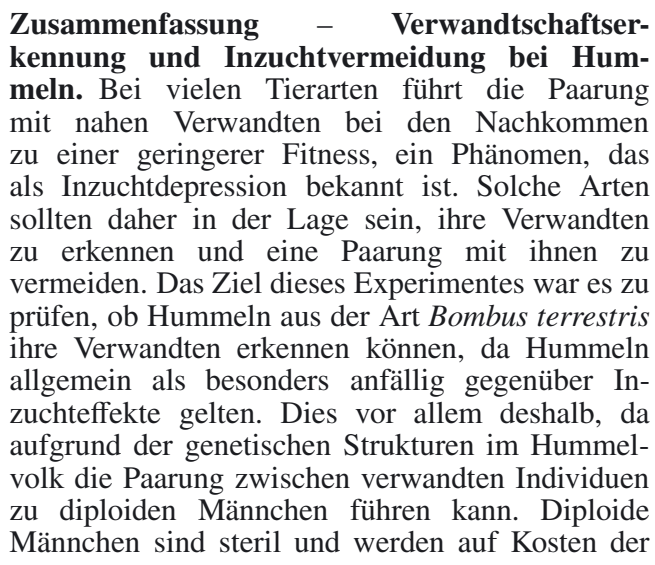


fleißigen Arbeiterinnen produziert, wodurch das Hummelvolk geschwächt wird. Daher sollte die natürliche Selektion zu Verwandtschaftserkennung und Inzuchtvermeidung führen, um die Kosten für die Produktion diploider Männchen zu umgehen. Das Paarungsexperiment wurde in einem großen Flugkäfig $(70 \mathrm{~cm} \times 70 \mathrm{~cm} \times 70 \mathrm{~cm})$ aus Gaze durchgeführt und den jungen Königinnen wurden entweder ihre Brüder oder unverwandte Männchen als Paarungspartner angeboten. Die Bereitschaft der Königinnen sich mit ihren Brüdern bzw. den unverwandten Männchen zu paaren wurde ermittelt, indem die Zeitspanne zwischen dem Freilassen der Paarungspartner (Königin und Männchen) und der erfolgreichen Kopulation gemessen wurde. Durchschnittlich 10,8 Minuten $( \pm 0,94)$ vergingen, bis eine Verwandtenpaarung stattfand, während im Durchschnitt lediglich 4,5 Minuten $( \pm 1,15)$ für eine Paarung zwischen nicht verwandten Partnern benötigt wurden. Diese Ergebnisse lassen vermuten, dass $B$. terrestris die Fähigkeit zur Verwandtschaftserkennung besitzt und entsprechend dem Verwandtschaftsgrad das Paarungsverhalten ändert. Weitere Untersuchungen sollten die Mechanismen der Verwandtschaftserkennung aufklären.

\section{Bombus terrestris / Paarung / Vermeidung von Inzucht / Haplodiploidie}

\section{REFERENCES}

Alford D.V. (1975) Bumblebees Davis-Poynter, London.

Ayabe T., Hoshiba H., Ono M. (2004) Cytological evidence for triploid males and females in the bumblebee, Bombus terrestris, Chromosome Res. 12, 215-223.

Baer B. (2003) Bumblebees as model organisms to study male sexual selection in social insects, Behav. Ecol. Sociobiol. 54, 521-533.

Barnard C.J., Aldhous P. (1991) Kinship, kin discrimination and mate choice, in: Hepper P.G. (Ed.), Kin recognition, Cambridge University Press, Cambridge, pp. 125-146.

Birkhead T.R., Pizzari T. (2002) Postcopulatory sexual selection, Nat. Rev. Genet. 3, 262-273.

Blaustein A.R. (1983) Kin Recognition Mechanisms - Phenotypic Matching Or Recognition Alleles, Am. Nat. 121, 749-754.

Colegrave N., Kotiaho J.S., Tomkins J.L. (2002) Mate choice or polyandry: reconciling genetic compatibility and good genes sexual selection, Evol. Ecol. Res. 4, 911-917.

Cook J.M., Crozier R.H. (1995) Sex determination and population biology in the Hymenoptera, Trends Ecol. Evol. 10, 281-286.
Darvill B., Ellis J.S., Lye G.C., Goulson D. (2006) Population structure and inbreeding in a rare and declining bumblebee, Bombus muscorum (Hymenoptera: Apidae), Mol. Ecol. 15, 601-611.

Djegham Y., Verhaeghe J.C., Rasmont P. (1994) Copulation of Bombus terrestris L. (Hymenoptera, Apidae) in captivity, J. Apicult. Res. 33, 15-20.

Duchateau M.J., Hoshiba H., Velthuis H.H.W. (1994) Diploid males in the bumble bee Bombus terrestris, sex determination, sex alleles and viability, Entomol. Exp. Appl. 71, 263-269.

Duchateau M.J., Marien J. (1995) Sexual biology of haploid and diploid males in the bumble bee Bombus terrestris, Insectes Soc. 42, 255-266.

Duvoisin N., Baer B., Schmid-Hempel P. (1999) Sperm transfer and male competition in a bumblebee, Anim. Behav. 58, 743-749.

Estoup A., Scholl A., Pouvreau A., Solignac M. (1995) Monoandry and polyandry in bumble bees (Hymenoptera - Bombinae) as evidenced by highly variable microsatellites, Mol. Ecol. 4, 8993.

Foster R.L. (1992) Nestmate recognition as an inbreeding avoidance mechanism in bumble bees (Hymenoptera, Apidae), J. Kansas Entomol. Soc. $65,238-243$.

Frommen J.G., Luz C., Bakker T.C.M. (2007) Kin discrimination in sticklebacks is mediated by social learning rather than innate recognition, Ethology 113, 276-282.

Gamboa G.J., Grudzien T.A., Espelie K.E., Bura E.A. (1996) Kin recognition pheromones in social wasps: Combining chemical and behavioural evidence, Anim. Behav. 51, 625-629.

Gerloff C.U., Ottmer B.K., Schmid-Hempel P. (2003) Effects of inbreeding on immune response and body size in a social insect, Bombus terrestris, Funct. Ecol. 17, 582-589.

Gerloff C.U., Schmid-Hempel P. (2005) Inbreeding depression and family variation in a social insect, Bombus terrestris (Hymenoptera: Apidae), Oikos 111, 67-80.

Halliday T.R. (1983) The study of mate choice, in: Bateson P. (Ed.), Mate choice, Cambridge University Press, Cambridge, pp. 3-32.

Herzner G., Schmitt T., Heckel F. Schreier P., Strohm E. (2006) Brothers smell similar: Variation in the sex pheromone of male European Beewolves Philanthus triangulum F. (Hymenoptera: Crabronidae) and its implications for inbreeding avoidance, Biol. J. Linnean Soc. 89, 433-442.

Holmes W.G., Sherman P.W. (1982) The ontogeny of kin recognition in two species of ground squirrels, Am. Zool. 22, 491-517.

Holmes W.G., Sherman P.W. (1983) Kin recognition in animals, Am. Sci. 71, 46-55.

Keller L., Passera L. (1993) Incest avoidance, fluctuating asymmetry, and the consequences of inbreeding in Iridomyrmex humilis, an ant with multiple 
queen colonies, Behav. Ecol. Sociobiol. 33, 191199.

Keller L., Ross K.G. (1998) Selfish genes: a green beard in the red fire ant, Nature 394, 573-575.

Kindl J., Hovorka O., Urbanova K., Valterova I. (1999) Scent marking in male premating behavior of Bombus confusus, J. Chem. Ecol. 25, 1489-1500.

Lihoreau M., Zimmer C., Rivault C. (2007) Kin recognition and incest avoidance in a group-living insect, Behav. Ecol. 18, 880-887.

Plowright R.C., Pallett M.J. (1979) Worker-male conflict and inbreeding in bumble bees (Hymenoptera-Apidae), Can. Entomol. 111, 289-294.

Pusey A., Wolf M. (1996) Inbreeding avoidance in animals, Trends Ecol. Evol. 11, 201-206.

Sauter A., Brown M.J.F. (2001) To copulate or not? The importance of female status and behavioural variation in predicting copulation in a bumblebee, Anim. Behav. 62, 221-226.

Schmid-Hempel R., Schmid-Hempel P. (2000) Female mating frequencies in Bombus spp. from Central Europe, Insectes Soc. 47, 36-41.

Shellman-Reeve J.S. (2001) Genetic relatedness and partner preference in a monogamous, wooddwelling termite, Anim. Behav. 61, 869-876.

Simmons L.W. (1989) Kin recognition and its influence on mating preferences of the field cricket, Gryllus bimaculatus (Degeer), Anim. Behav. 38, 68-77.

Smith B.H., Ayasse M. (1987) Kin-based male mating preferences in two species of halictine bee, Behav. Ecol. Sociobiol. 20, 313-318.
Smith B.H., Wenzel J.W. (1988) Pheromonal covariation and kinship in social bee Lasioglossum zephyrum (Hymenoptera, Halictidae), J. Chem. Ecol. 14, 87-94.

Takahashi J., Ayabe T., Mitsuhata M., Shimizu I., Ono M. (2008) Diploid male production in a rare and locally distributed bumblebee, Bombus florilegus (Hymenoptera, Apidae), Insectes Soc. 55, 43-50.

Tang-Martinez Z. (2001) The mechanisms of kin discrimination and the evolution of kin recognition in vertebrates: a critical re-evaluation, Behav. Proc. $53,21-40$.

Tasei J.N., Moinard C., Moreau L., Himpens B., Guyonnaud S. (1998) Relationship between aging, mating and sperm production in captive Bombus terrestris, J. Apicult. Res. 37, 107-113.

Todrank J., Heth G. (2003) Odor-genes covariance and genetic relatedness assessments: rethinking odour based "recognition" mechanisms in rodents, Adv. Study Behav. 32, 77-130.

Tregenza T., Wedell N. (2002) Polyandrous females avoid costs of inbreeding, Nature 415, 71-73.

Whitehorn P.R., Tinsley M.C., Brown M.J.F., Darvill B., Goulson D. (2009) Impacts of inbreeding on bumblebee colony fitness under field conditions, BMC Evol. Biol. 9, 152.

Williams P.H. (1991) The bumble bees of the Kashmir Himalaya (Hymenoptera: Apidae, Bombini), Bull. Br. Mus. Nat. Hist. (Entomol.) 60, 1-204.

Zayed A., Packer L. (2005) Complementary sex determination substantially increases extinction proneness of haplodiploid populations, Proc. Natl Acad. Sci. (USA) 102, 10742-10746. 